\title{
YESUS KRISTUS SANG JALAN : KRISTOLOGI KONTEKSTUAL BAGI PENGHAYAT KEBATINAN KATOLIK
}

\author{
Martinus Joko Lelono
}

\begin{abstract}
:
After His Resurrection and Ascension, the disciples tried to understand who Jesus really was. Thus, the formulations of Jesus as 'God with us', 'Son of God', 'Christ' and so forth, came into their consciousness. These formulations were growing in accordance with the particular social context in which the Christian faith was proclaimed. An attempt to find a formula of Jesus Christ in various contexts is what is known as the contextual Christology. The emergence of liberation theology in the second half of the 20th century gave birth to the realization that theology always has a context, has a background and also deals with particular concerns. Therefore, Christology as one of the branches of theology also needs to pay attention to the context. Contextual Christology for the Javanese Catholic mystics encourages the followers of Jesus Christ to always walk with Him. Given that He is no longer present in the earthly form, the presence of spiritual formation and mystical exercise in a personal relationship with Jesus Christ are to be pursued. This is where the role of the Holy Spirit, as Jesus' promised helper, is present. In every prayer and mystical exercise of the Javanese Catholic mystics, the assertion in the Holy Spirit that Jesus Christ is the Way is experienced. The ultimate goal of all this is a full union with God the Father, the Son and the Holy Spirit in the House of the Father (cf. Jn 14:2).
\end{abstract}

\section{Kata-kata Kunci:}

Kristologi, kebatinan, kontekstual, iman, Jawa, pastoral.

\section{LATAR BELAKANG}

Di Keuskupan Agung Semarang (KAS) setiap tahun diadakan acara Temu Kebatinan bagi penghayat Kebatinan Katolik. ${ }^{1}$ Mereka yang bertemu adalah para penghayat Kebatinan yang umumnya beragama Katolik. J. Darminta, SJ. Merumuskan kebatinan sebagai: "Hidup manusia sejauh itu bergaul dengan Allah. Setiap kali orang mengundurkan diri dari segala kesibukan sehari-hari dan menyempatkan diri untuk merefleksikan hidup dan diri, dikatakan orang mengolah hidup. Bila pengolahan hidup didasarkan pada prinsip- prinsip hidup rohani menurut iman dan kepercayaan yang dianutnya, maka orang itu masuk ke dalam hidup batin atau lebih tepat hidup rohani. Kebatinan merupakan dimensi hidup manusia yang mempengaruhi manusia seluruhnya, entah itu sistem nilai yang dipilih, keutamaan-keutamaan yang dipupuk, sikap-sikap hidup yang dikembangkan maupun tindakan-tindakan hidup yang dipilih."2

Temu kebatinan merupakan usaha KAS untuk mengakomodasi umat yang menghayati iman Katolik dalam tradisi kebatinan Jawa. Pada tahun 1996, dalam 
rapat Dewan Karya Pastoral KAS muncul keprihatinan berhubungan dengan umat Katolik yang masuk dalam aliran kebatinan lintas teritorial dan lintas agama-kepercayaan. Mereka adalah umat Katolik yang masih mencari kemantapan penghayatan iman menurut citarasa budayanya. ${ }^{3}$ Menghadapi situasi itu, keuskupan menggagas sebuah wadah untuk mengakomodasi penghayatan iman mereka. Wadah itulah yang dikenal sebagai acara Temu Kebatinan. Umat yang terlibat umumnya para penghayat kebatinan. Dalam tiap pertemuan diadakan dialog yang dibantu oleh satu atau beberapa narasumber. Di dalamnya digagas usaha pemaknaan perjumpaan antara iman Katolik dan budaya Jawa. ${ }^{4}$ Temu Kebatinan ini berperan penting untuk menemukan titik temu antara budaya Jawa dengan iman Katolik. Tema-tema yang diangkat dalam pertemuan ini sangat luas, tetapi titik utamanya adalah untuk menemukan pemaknaan iman khas Katolik-Jawa.

Usaha untuk menyapa para Penghayat Kebatinan Katolik menjadi pekerjaan rumah dari Gereja KAS. Selama ini pengolahan-pengolahan bersama sudah dilakukan. Hanya, selalu disadari bahwa ada tegangan antara menghidupi iman Katolik dan budaya Jawa. Meski terdapat banyak hal yang selaras, terdapat hal yang tidak selaras antara Agama Katolik dan Budaya Jawa. Tegangan antara menjadi sinkretik dan menjadi puritan Katolik terus menerus menjadi pekerjaan rumah yang perlu digeluti. Maka masalah utama yang hendak dikaji adalah 'bagaimana para penghayat kebatinan menangkap dan memaknai tegangan antara iman Katolik dan tradisi Kebatinan Jawa, terutama dalam menangkap makna kehadiran Yesus Kristus?'

Yesus Kristus adalah tokoh sentral kekatolikan. Sementara budaya Jawa punya cara sendiri memaknai kehadiran Yang Ilahi. Sebagai sebuah cabang ilmu pengetahuan, teologi mencoba membahasakan arti kehadiran Allah di tengah masyarakat. Iman Katolik tidak pernah menjadi isapan jempol saja, melainkan perlu menjadi bagian integral dari masyarakat, punya suara dan kehadirannya bermakna bagi kehidupan bersama. Untuk itu, pendekatan iman berbasis budaya dirasa kian penting.

\section{IMAN DAN KULTUR}

Berbicara mengenai paham ketuhanan, tentu harus pula membicarakan pengalaman religius. Menurut Mircea Eliade, pengalaman religius adalah titik temu antara Yang Ilahi dan manusia. Dibedakan dari pengalaman iman yang mengacu pada pewahyuan tertentu, ${ }^{5}$ pengalaman religius adalah pengalaman murni manusia berhadapan dengan Yang Ilahi. Eliade menyebut mereka yang mengalami pengalaman religius sebagai manusia religius. ${ }^{6}$ Kepekaan religius manusia kuno terbentuk melalui kehidupan sehari-hari di mana mereka dekat dengan alam yang menampakkan kehadiran Yang Ilahi, sementara manusia modern menyediakan waktu khusus agar mampu mengalami kehadiran Yang Ilahi dalam kehidupannya. Pendirian tempat ibadah menjadi salah satu contohnya. Di Jawa, pengalaman religius itu terus dialami dalam proses menghidupi iman dan budaya. Dalam konteks Jawa, diperlukan pendekatan khusus mendekatkan agama dan budaya mengingat agamaagama yang dianut berasal dari luar kebudayaan asli masyarakat Jawa.

Perlunya pendekatan khusus menghadirkan agama di Jawa ini, tampak dalam pewartaan Islam-Jawa. Perpaduan antara mistik Islam dan mistik Kejawen memunculkan kesadaran akan perasaan dekat dengan Allah yang dari awal menjadi kerinduan masyarakat Jawa. Rumusan Manunggaling Kawula lan Gusti menjadi rumusan yang amat berbicara bagi masyarakat Jawa yang memerlukan petunjuk hidup. Dalam bahasan Zoetmulder, Manunggaling Kawula lan Gusti menjadi titik temu untuk menghidupkan iman Islam di kalangan masyarakat Jawa. Sementara dalam bahasa Simuh perjumpaan itu dikenal dalam usaha kompromis-nonkompromis. Ada saatnya pendekatan yang fokus pada budaya diangkat, tetapi tetap disadari adanya ketegangan yang membedakan antara pemaknaan orang Jawa akan Yang Ilahi dan apa yang diwar-takan oleh Islam. Bentuk perjumpaan ini bisa menjadi 
pembelajaran yang baik untuk semakin membumikan agama Katolik di tanah Jawa.

Dalam mempertemukan iman dan budaya, usaha trial dan error perlu diapresiasi. Tiap kesalahan akan membawa pembelajaran tersendiri bagi umat. Namun, warna Gereja yang membawa misi keterbukaan sering tertutupi oleh keinginan untuk membawa monokultur di dalam geraknya. Amaladoss membantu menemukan tegangan antara Gereja Universal dan Gereja Lokal. Ia memakai istilah 'sungguh menjadi Gereja lokal yang universal' untuk memaknai arti kehadiran Gereja yang kontekstual. Amaladoss berharap proses ini membantu menemukan keotentikan ungkapan pengalaman religius umat. Suasana kreatif dan merdeka perlu diusahakan agar perjumpaan antara iman dan kultur menjadi penghayatan hidup.

Teori-teori di atas memberi kerangka pikir atas usaha pendekatan pastoral yang tepat bagi penghayat Kebatinan Katolik. Penelitian ini mencoba menjawabnya.

\section{MELIHAT KEMUNGKINAN PASTORAL BAGI MASYARAKAT BERBUDAYA JAWA}

Di Indonesia, puncak pewartaan yang memerhatikan perjumpaan agama dan budaya terjadi di Jawa dengan tokohnya Pater Frans van Lith, SJ (selanjutnya disebut dengan Pater van Lith). Pembaptisan 171 orang di Sendangsono, daerah perbukitan Kalibawang Yogyakarta pada tahun 1904 oleh Pater van Lith disebut sebagai awal mula lahirnya umat Katolik di Jawa Tengah dan juga wilayah yang sekarang dikenal sebagai wilayah Gerejani KAS. ${ }^{7}$ Dalam pewartaannya, Pater van Lith menggunakan cara yang khas. Ada prinsipprinsip yang dipegang oleh misionaris ini. Tom Jacobs mencatat bahwa Pater van Lith memandang penting mengenal agama masyarakat. Tom Jacob menuliskan, "Dalam suatu karangan ilmiah dari tahun 1924, ia membahas sebuah naskah bahasa Jawa Kuno, di mana termuat doa kepada Syiwa. Pada akhir karangan itu ia menulis: 'Seorang misionaris yang ingin membawa Injil ke dalam hati saudara-saudaranya yang bukan kristiani, harus tahu betul-betul mengenai agama itu. Itulah ajaran pokok yang harus kita simpulkan dari doa syukur bagus ini kepada Syiwa. Kalau para misionaris tidak tahu menahu mengenai semua itu, maka tidak ada jalan temu dengan hati para pendengar dan tidak mungkin menyampaikan kebenaran yang ia bawa. Malahan ia akan kehilangan kepercayaan dan cinta kasih para pendengarnya." 8

Prinsip Pater van Lith itu diterapkan dalam menerjemahkan doa-doa dasar. Pater van Lith dan Pater Hoevenaars hidup sebelum Konsili Vatikan II. Pada waktu itu kebanyakan buku doa Gereja masih memakai bahasa Latin, tetapi umat membutuhkan rumusan doa dalam bahasa lokal. Buku Gereja dalam bahasa daerah terbatas pada buku katekismus dengan doa-doa harian yang terbatas. Usaha penerjemahan ini menjadi penting maka segera diusahakan. Namun, dalam prosesnya, terjadi konflik antara Pater van Lith dengan Pater Hoevenaars. Pater van Lith membutuhkan waktu lama untuk menerjemahkan doa-doa itu, sementara Pater Hoevenaars hanya butuh waktu pendek. Pater Hoevenaars mengambil alih saja terjemahan protestan. Pater van Lith marah ketika Pater Hoevenaars tanpa konsultasi sudah mengeluarkan buku dalam cetakan kedua. Bagi Pater Hoevenaars buku pelajaran agama, lengkap dengan doa-doanya hanyalah alat bantu yang harus ada tetapi tidak begitu penting. Bagi Pater van Lith hal ini mahapenting, sebab di dalamnya terungkap inti perasaan hati. Pater van Lith tidak berpangkal pada teks Belanda dan Latin, melainkan apa yang hidup dalam hati orang Jawa. Ia memegang teguh bahwa penerjemahan bukan sekadar kata demi kata, melainkan ungkapan yang lain dengan kata yang lain. Pater van Lith menganggap penting arti dan perasaan yang mau diungkapkan oleh doa itu. Karena itu, pertanyaan pokoknya ialah, "Apa yang terjadi dalam hati seseorang, kalau ia mendengar atau membaca doa-doa Gereja dalam bahasanya sendiri?"

Belajar dari pendekatan yang dibuat oleh misi di Indonesia awal dengan kesulitannya, ditemukan perlunya cara pendekatan khusus pada masyarakat dalam karya 
misi. Bermisi bukan berarti hanya membaptis sebanyak mungkin orang melainkan terlibat dalam kehidupan mereka, mendengarkan budaya dan 'agama' mereka serta mencoba meneranginya dalam terang Injil. Pater van Lith adalah tokoh yang berhasil masuk dalam pola pikir, dan rasa orang Jawa. Ia hadir di antara mereka, berbicara dalam bahasa mereka dan akhirnya menyapa mereka secara personal. Tentu hal ini menjadi pembelajaran yang berguna untuk melihat karya misi saat ini termasuk di lingkup KAS.

\section{KRISTOLOGI KONTEKSTUAL DALAM KONTEKS KEBATINAN KATOLIK}

Salah satu cabang teologi adalah kristologi. Kristologi adalah cabang teologi yang penting hal ini mengingat bahwa pusat dari Kitab Suci Perjanjian Baru adalah memperkenalkan Yesus Kristus dan gerakan-Nya. Karena Yesus dan gerakan-Nya mempunyai makna bagi semua orang senantiasa dan di manapun (universal), maka juga untuk situasi konkret dan aktual kita di tempat kita berada saat ini (partikular). ${ }^{9}$

Kebatinan Katolik muncul dari dorongan untuk melakukan olah batin guna mendalami iman, menjadikannya milik dan menyatakannya dalam tindakan. Ada dorongan untuk tidak hanya melakukan yang biasa melainkan mengolah batin sehingga mencapai yang baik dalam kehidupan. Berbeda dari olah kebatinan Jawa (yang dikenal juga sebagai Kejawen), kebatinan Katolik mengacu pada iman Katolik dan mendasarkan pengolahannya dengan menggunakan ayat Kitab Suci. Namun, dalam hal metode dan beberapa sumber tambahan, apa yang ada dalam kebatinan Jawa masih dihidupi oleh para penghayat Kebatinan Katolik. Dengan cara itu, iman lebih dirasakan kehadirannya karena mengakar pada olah batin dan penghayatan ketuhanan dalam tradisi Jawa. Para penghayat kebatinan Katolik juga tidak melepaskan kebiasaan dasar umat Katolik untuk mengikuti perayaan Ekaristi setiap hari Minggu. Pada umumnya, mereka mengikuti perayaan Ekaristi mingguan. Hal ini menunjukkan bahwa pengolahan
Kebatinan Katolik tidak menjauhkan mereka dari ritual Gereja Katolik.

Berhubungan dengan momen-momen khusus pengolahan batin, penghayat kebatinan Katolik menyediakan waktu khusus untuk mengolah batin, baik dalam perayaan Ekaristi maupun dalam waktuwaktu yang disediakan khusus untuk olah batin. Karena mereka adalah bagian dari masyarakat Jawa, maka beberapa pengolahan batin sebagian dilakukan dengan metode khas Jawa. Data menunjukkan bahwa meski sebagian besar tidak lagi menggunakan Kitab-kitab kebijaksanaan Jawa, tetapi mereka menggunakan laku tapa dan puasa Jawa. Sebagian besar responden mengatakan bahwa mereka menggunakan laku puasa dengan cara kejawen untuk mendukung olah batin mereka.

Bentuk pengolahan batin yang masih mengakomodasi unsur-unsur religius lokal dikembangkan juga dalam proses kontekstualisasi iman Islam. Nyatanya, iman ini bisa mengakar dan hidup di tengah kehidupan orang Jawa. Metode positif ini coba dipelajari sebagai metode yang berhasil menghidupkan iman dalam konteks lokal. Belajar dari konsep Simuh mengenai metode dakwah kompromis-nonkompromis, kita melihat adanya kesamaan dengan usaha mengakomodasi iman para penghayat kebatinan Katolik. Hal ini senada dengan pembahasan Zoetmulder mengenai keragu-raguan dalam konsep Manunggaling Kawula lan Gusti. Demikian pula Simuh memandang bahwa dalam pandangan Manunggaling Kawula lan Gusti yang dikembangkan dalam Islam Jawa terdapat keragu-raguan dalam hal kesatuan antara Allah dan manusia. Tegangan antara kesatuan yang dikembangkan dalam religiusitas lokal dan keterpisahan dalam agama Islam memunculkan pandangan tentang Manunggaling Kawula lan Gusti dalam tradisi Islam Jawa.

Dalam analisis data kuantitatif ditunjukkan bahwa Manunggaling Kawula lan Gusti merupakan konsep Jawa yang diterima oleh para penghayat Kebatinan Katolik. Namun, data kualitatif menunjukkan bahwa konsep ini dimaknai secara baru dengan ungkapan Manunggaling Gusti 
lan Kawula. Hal ini tidak sekedar rumusan baru melainkan sebuah hasil kontekstualisasi iman (kompromis-nonkompromis). Ungkapan Manunggaling Gusti lan Kawula memaknai perbedaan usaha olah batin Jawa dengan olah batin Katolik. Olah batin Jawa menitik-beratkan pada usaha manusia menggapai Yang Ilahi sementara olah batin Katolik berarti menanggapi sapaan Allah. Di satu sisi ungkapannya senada, tetapi di sisi lain rumusan ini diselaraskan dengan ajaran iman Katolik. Rumusan ini diterima oleh para penghayat kebatinan Katolik yang terungkap dalam data wawancara.

Data ini memberi gambaran senada dengan hasil penelitian Simuh dan Zoetmulder mengenai kompromis-nonkompromis dan keragu-raguan mengenai konsep kesatuan dalam Islam Jawa. Dalam konteks penghayat Kebatinan Katolik proses perjumpaannya juga tidak bisa seratus persen. Namun, dengan menggunakan konsep yang dekat dengan budaya Jawa, pewartaan iman Katolik menjadi lebih diterima. Di sini, baik konsep Jawa maupun iman Katolik tidak diabaikan. Ungkapan Manunggaling Gusti lan kawula, sekaligus mengakui adanya inisiatif dari Allah untuk menyapa manusia, dan mengakui usaha kesatuan manusia menanggapi sapaan dari Allah.

Selanjutnya, dua teori utama Mircea Eliade: teori axis mundi; teori 'waktu profan dan waktu kudus' membantu memahami bagaimana penghayatan iman penghayat Kebatinan Katolik. Axis mundi atau pilar dunia dalam pandangan Mircea Eliade mempertemukan manusia dengan Yang Ilahi, tempat di mana dunia dan surga terhubung $^{10}$. Dalam kerangka teori Mircea Eliade, axis mundi itu berwujud tempat tertentu yang dianggap bisa mempertemukan manusia dengan Tuhan. Penghayat kebatinan Katolik mengalami perjumpaan dengan Allah dalam pengalaman doa, baik di Gereja maupun di tempat-tempat khusus lainnya seperti di makam; dalam kamar sendiri; dalam pendopo samping rumah; ataupun di tempat peziarahan seperti di Gua Maria Sendangsono dan Candi Hati Kudus Tuhan Yesus Ganjuran. Namun, proses yang sedang diusahakan adalah agar perjumpaan dengan Allah ini dialami di mana pun mereka berada. Mereka hendak membangun kepekaan batin untuk bisa mengenal kehadiran Allah dalam setiap pengalaman. Membaca pola yang dibangun oleh penghayat kebatinan Katolik ini, tampak adanya usaha kembali ke pola relasi masyarakat kuno dengan Yang Ilahi sebagaimana dipahami oleh Mircea Eliade. Masyarakat modern membangun kepekaan religiusnya dalam situasi yang sudah dikondisikan seperti halnya melalui ritusritus di tempat-tempat ibadah, sementara masyarakat kuno mengalaminya dalam relasi yang dekat dengan kehidupan seharihari. ${ }^{11}$ Maka, dengan mengusahakan olah batin di sepanjang hidup harian, orang setiap kali berusaha selalu terhubung dengan surga (axis mundi).

Berhubungan dengan waktu profan dan waktu kudus, penghayat kebatinan Katolik mengalami pengalaman khusus, baik dalam Ekaristi, meditasi, olah refleksi melalui tulisan, maupun pertemuan-pertemuan kelompok kebatinan. Mereka mengkhususkan diri untuk mengolah batin agar relasi pribadi dengan Allah semakin terjaga. Hal ini lebih kentara dengan proses olah batin berdasarkan Sabda Allah dalam Kitab Suci. Ada hubungan timbal balik antara Allah dan manusia: Allah yang menyapa melalui sabda dan manusia menanggapi melalui kehadiran pribadi. Namun, ada kalanya mereka harus menjalani pengalaman harian yang profan. Dalam saat-saat itulah kepekaan pada kehadiran Allah menjadi kekuatan. Maka, arah dari proses pengolahan waktu kudus adalah agar kedekatan dengan Allah semakin menginspirasi dan menjadi pedoman ketika orang menjalani kehidupan pada waktu profan kehidupannya.

Demikianlah penghayat Kebatinan Katolik menghidupi imannya dalam tegangan antara bersatu dengan Tuhan dan terpisah daripada-Nya, antara ada bersama Dia dan ada dalam kehidupan harian serta antara terhubung dengan Dia dan terpisah daripada-Nya. Tegangan-tegangan ini menghantar pada pemahaman bahwa iman terus dinamis, berjalan dan mengarah pada suatu kesatuan penuh dengan Allah. 


\section{Yesus Kristus Sang Jalan Menurut Tradisi Teologis}

Rumusan Yesus Kristus Sang Jalan adalah rumusan yang mengacu pada sabda Yesus dalam Yohanes 14: 5-7 berikut:

Kata Thomas kepada Yesus: "Tuhan, kami tidak tahu ke mana Engkau pergi; jadi bagaimana kami tahu jalan ke situ?" Kata Yesus kepadanya: "Akulah jalan dan kebenaran dan hidup. Tidak ada seorang pun yang datang kepada Bapa, kalau tidak melalui Aku. Sekiranya kamu mengenal Aku, pasti kamu juga mengenal Bapa-Ku. Sekarang ini kamu mengenal Dia dan kamu telah melihat Dia." (bdk. Yoh 14: 57).

Dalam teks inilah Yesus mewahyukan diri sebagai jalan menuju kepada Bapa. Teks ini sekaligus mewahyukan apa sebenarnya tujuan akhir perjalanan mengikuti Yesus. Perjalanan itu berakhir pada kesatuan dengan Bapa di surga. Dalam ungkapan perpisahan Yesus dengan para muridnya, Yesus mengingatkan bahwa mereka sudah didampingi oleh Yesus dan tahu ke mana Yesus akan melangkah. Para murid sudah mendengar bahwa Yesus akan kembali kepada Bapa melalui nubuat Yesus tentang pengalaman kematian-Nya dan bagaimana kebangkitan-Nya akan menunjukkan kemuliaan Allah. Pertanyaan Thomas pada perikop ini menampilkan ketidakmauan para murid untuk menghadapi akhir kisah Yesus. Ada kegamangan dalam diri para murid menghadapi perpisahan dengan Yesus. Dalam situasi ini, Yesus meneguhkan bahwa apa yang ditinggalkan Yesus bagi mereka sudahlah cukup. Yesus adalah jalan untuk sampai kepada Bapa. Pernyataan Yesus sebagai jalan bukan hanya sekedar pernyataan diri. Dia tidak hanya menyatakan siapa dirinya, tetapi juga apa yang Ia kerjakan. Segala sesuatu yang dia perbuat, dan semua ajarannya adalah jalan yang akan menghantar para murid untuk sampai kepada Bapa. Allah menyatakan diri dalam Hidup dan Sabda Yesus. Selanjutnya, para murid harus tahu bahwa keberangkatan Yesus menuju Bapa akan melampaui kehidupan dan kematian. Jalan Yesus adalah sebuah jalan cinta dan pemberian diri total sampai kepada kematian. Para pengikut-Nya harus mengikuti jalan yang sama. Bagian ini dimulai dengan desakan yang kuat agar para murid percaya dan yakin akan Bapa. Yesus menyadarkan para murid agar menerima konsekuensi menjadi pengikutNya. Bagian ini diakhiri dengan alasan mengapa kebimbangan para murid harus dienyahkan. Mereka harus yakin bahwa jalan ini adalah jalan yang benar menuju pada Allah. Percaya dan yakin kepada Yesus adalah satu-satunya jalan agar sampai pada tujuan akhir yaitu kesatuan dengan Bapa. ${ }^{12}$

Ungkapan "Yesus Sang Jalan" menunjukkan bahwa yang Ia kerjakan se-matamata adalah melakukan apa yang Bapa kehendaki terjadi di dunia ini. Tindakan itu bukan tindakan Allah yang tak tersentuh oleh kelemahan dan kekurangan, tetapi tindakan Yesus sebagai manusia yang sekaligus Allah. Ia juga mengalami kemanusiaan tetapi berusaha semakin sekehendak dengan Allah. Hal ini ditegaskan dalam sabda pada Injil Yohanes, "Makanan$\mathrm{Ku}$ ialah melakukan kehendak Dia yang mengutus Aku dan menyelesaikan pekerjaan-Nya” (bdk. Yoh 4: 34). Yesus tidak hanya mengajar melalui kata-kata, tetapi juga bekerja untuk mewujudkan ajaranNya.

Meski ungkapan Yesus Kristus Sang Jalan menjadi kajian utama, tidak bisa dipungkiri bahwa ketiganya (jalan, kebenaran, dan hidup) adalah kesatuan. Keinginan dan gerak mencari kebenaran menjadi sesuatu yang baru dalam Perjanjian Baru karena pengetahuan akan kebenaran menunjukkan kedewasaan dalam iman. Melalui kebenaran inilah para pengikut Yesus telah beralih dari masa muda ke masa dewasa. Hukum berproses dari Allah yang tak kelihatan yang selalu membuat janji kepada Israel dan keturunannya dalam Perjanjian Lama menuju kepada relasi personal dengan Yesus Kristus dalam Perjanjian Baru. Hukumhukum perjanjian lama adalah peraturan lokal; yang relevan dalam kasus tertentu atau peristiwa manusiawi tertentu dan peran ini diterima untuk sementara waktu. Sementara, kehadiran Yesus secara jelas menyampaikan hukum dan kebenaran baru: rahmat dan kebenaran dari kehendak Allah yang hadir melalui pribadi 'Sang 
Kebenaran' sendiri. Rahmat dan kebenaran terdapat dalam kehadiran Yesus. Umat Allah tidak lagi hanya mendengarkan dan taat tetapi sungguh melihat, dan memahami secara langsung. Ketika Sang Kebenaran di atas segala kebenaran tampil, lalu pembelajaran dan kontemplasi tentang kebenaran mendorong manusia untuk mengambil peran secara langsung dalam semua perasaan, pikiran dan tindakan Allah. Kehadiran Allah merupakan sebuah panggilan kepada iman yang dialami dalam beberapa pengalaman. Namun, pengembangan iman membutuhkan pema-haman baru dalam pengalaman-pengalaman harian. Ketika manusia mulai belajar kebenaran aktual berhubungan dengan manusia dan alam semesta, Allah akan menganugerahkan pengetahuan akan pentingnya kehadiran Allah. Jika kebenaran yang ada dalam Injil tidak cukup meyakinkan sebagai kebenaran maka iman kepada Yesus Kristus menjadi tidak bermakna. Jika Kristus tidak secara sempurna menjadi jalan khusus menuju kebenaran, maka iman kepada-Nya pada dasarnya sudah tak bermakna. ${ }^{13}$ Selanjutnya, kehadiran Yesus menunjukkan bahwa Allah secara luar biasa menganugerahkan kehidupan dengan cara yang kadang tampak mustahil: hal ini ditampakkan misalnya melalui mukjizat penggandaan roti dan ikan. Dalam kehidupan real hal ini tampak dalam hubungan saling melengkapi antar makhluk hidup. Keberlangsungan hidup makhluk hidup bergantung pada apa yang ia terima dari makhluk lain. Tanpa ketersediaan makanan yang cukup dari makhluk lain, setiap makhluk pasti akan mati. Dalam peristiwa penggandaan lima roti dua ikan, Yesus menerima makanan dari para rasul, memberkatinya dan kemudian membagikannya kembali melalui tangan-tangan para rasul. Itulah tindakan pembaharuan hidup yang berawal dari Dia, ditampilkan dalam bentuk hal-hal yang duniawi dan disampaikan melalui manusia. Dengan cara ini Yesus Kristus menampilkan pemeliharaan-Nya bagi kehidupan manusia dan tujuan serta kuasa-Nya untuk menggapai dan menyelamatkan manusia. Dalam peristiwa nyata kehidupan sehari-hari inilah Allah dikenal secara baru melalui berbagai bentuk cinta kasih antar manusia.
Dalam semangat hidup seperti ini orang bisa menerima dukacita dan juga sukacita. Keduanya adalah bagian dari hidup dan mengajari manusia untuk segera bangkit dalam segala situasi kehidupan. Dia hadir secara dekat kepada seorang bapak, kepada seorang janda, kepada para saudari dan kepada para Guru. Kehadirannya dirasakan dalam kekalutan kehidupan dan penderitaan. Karya penyelamatan-Nya hidup dalam cinta kasih mereka, hidup bagi mereka dalam perasan simpati orang-orang di sekitar dan hadir dalam iman kepada Bapa yang dialami oleh setiap pribadi. Seperti halnya Yesus memberi makan kepada orang-orang yang lapar, demikian juga Dia hadir tak hanya sebagai penyembuh dari luka-luka tetapi juga pembaharu kehidupan dan menggandakan kebahagiaan. ${ }^{14}$

Membaca penjelasan ini orang lalu memahami bahwa Yesus sungguhlah Sang Jalan, Sang Kebenaran dan Sang Hidup. Dalam hal ini tak ada keraguan akan arti kehadiran Yesus sebagai Jalan, Kebenaran dan Hidup. Hal ini sekaligus menjadi penjelasan dari kesaksian Yohanes Pembaptis pada Yohanes awal injil Yohanes ketika dia mengatakan, "Tidak seorang pun yang pernah melihat Allah; tetapi Anak Tunggal Allah, yang ada di pangkuan Bapa, Dialah yang menyatakan-Nya" (bdk. Yoh 1: 18). Hal ini juga diungkapkan Yesus kepada Thomas, "Sekiranya kamu mengenal Aku, pasti kamu juga mengenal Bapa-Ku. Sekarang ini kamu mengenal Dia dan kamu telah melihat Dia" (bdk. Yoh. 14: 7). ${ }^{15}$

Paus Yohanes Paulus II menyebut bahwa kehadiran Yesus di dunia ini memiliki dua arti. Arti pertama adalah mewahyukan diri Allah dan arti kedua adalah mengungkapkan bagaimana menjadi manusia yang sesungguhnya. Yesus Kristus menyatakan rencana Allah Bapa untuk menyelamatkan dunia dan seluruh ciptaan melalui pernyataan "siapa dia" dan "apa yang dia kerjakan dalam kehadirannya". Belajar dari ungkapan Paus Yohanes Paulus II, kehadiran Yesus Kristus tampil dalam kehendak untuk menjadi saudara bagi yang lain dalam proses menuju Bapa yang satu yang ada di surga. Dalam proses itu, manusia terus menerus membangun pengharapan akan kebersamaan di rumah 
Bapa, meski dalam batas tertentu kesatuan dengan Bapa sudah terjadi saat ini. Jurgen Moltmann menyebutnya sebagai orientasi eskatologis, menanti kedatangan Tuhan kedua kalinya. Teologi harapan berpengaruh besar untuk menghidupkan harapan eskatologis. Teologi harapan eska-tologis inilah yang membantu menunjukkan makna dari "Yesus Kristus Sang Jalan”.

Saat ini Yesus Kristus tidak lagi hadir secara fisik dalam tindakan maupun sabda, namun dalam amanat perpisahannya Ia mengatakan bahwa akan ada penolong yang lain yang akan membantu para pengikutNya dalam mengikuti diri-Nya. Penolong itu adalah Roh Kudus. Yesus mengatakan, ""Jikalau kamu mengasihi Aku, kamu akan menuruti segala perintah-Ku. Aku akan minta kepada Bapa, dan Ia akan memberikan kepadamu seorang Penolong yang lain, supaya Ia menyertai kamu selamalamanya, yaitu Roh Kebenaran. Dunia tidak dapat menerima Dia, sebab dunia tidak melihat Dia dan tidak mengenal Dia. Tetapi kamu mengenal Dia, sebab Ia menyertai kamu dan akan diam di dalam kamu" (bdk. Yoh 14: 15-17). Secara konkret Federasi Konferensi-Konferensi Para Uskup Se-Asia (FABC) berbicara mengenai arti kesatuan kehidupan manusia dengan kehidupan ilahi bersama dengan Bapa-Putra dan Roh Kudus pada zaman ini. Dalam rapatnya pada 1995 di Hongkong, FABC membicarakan tentang dua proses kehidupan yang mempersatukan kehidupan manusia dan kehidupan Allah yang Ilahi. Pada masa kini terjadi disharmoni yang disebabkan oleh manusia. Dalam situasi itu Yesus Kristus hadir sebagai pembawa keselarasan. Pemulihan keselarasan ini terjadi melalui Yesus Kristus. Oleh karenanya, di antara manusia pada umumnya yang menyebabkan disharmoni, manusia pengikut Yesus Kristus diundang untuk membawa keselarasan.

Yesus Kristus merobohkan dinding pemisah, yang didirikan oleh keserakahan, kesombongan, diskrimansi, norma-norma sosial yang berat sebelah dan bahkan distorsidistorsi keagamaan. Sampah masyarakat menjadi saudara-saudari. Para pendosa layak menerima belas kasihan. Orangorang yang lapar, haus, narapidana, dan telanjang menjadi tanda kehadiran ilahi. Allah ialah Bapa kita. Dalam kebebasan dan persekutuan dalam Yesus, menyingsinglah fajar penciptaan baru. Masyarakat manusia dilahirkan ulang. Memang sudah tibalah saat pemenuhan. Hidup yang berkelimpahan ada di tengah kita. Kerajaan sudah ada di tengah kita. ${ }^{16}$

Usaha para pengikut Kristus untuk menggerakkan masyarakat peduli kepada sesama, tidak bisa terwujud dalam metode tunggal. Kesadaran akan konteks masyarakat dengan budayanya perlu disadari sebagai bagian dari proses membawa keselarasan. Konsep Amaladoss mengenai bagaimana menghidupkan gerakan Yesus Kristus dalam budaya setempat meneguhkan refleksi FABC di atas. Amaladoss menuturkan, "Perlu disadari bahwa proses perjumpaan interkultural dan interreligius tidak pernah berjumpa dengan masyarakat yang nirbudaya. Proses perjumpaan interkultural dan interreligius adalah sebuah proses dinamis yang terus menerus. Untuk mencapai tujuan ini, keterlibatan umat setempat yang menghayati budaya tertentu perlu mendapat tekanan sehingga Injil menjiwai dan menciptakan sebuah budaya dalam bentuk yang baru dan berdaya guna. Dalam hubungannya dengan 'agama-agama' dalam budaya, proses inkulturasi perlu memperhatikan aspek spiritualitas. Tentulah perlu ada usaha perjumpaan antar keduanya.

\section{“Yesus Kristus Sang Jalan” bagi Penghayat Kebatinan Katolik}

Kristologi Yesus Kristus Sang Jalan menekankan aspek mengikuti sambil menjadi teman seperjalanan. Ada saatnya Yesus Kristus hadir sebagai pribadi yang menunjukkan arah sambil tetap memberi tekanan kepada arti pergulatan pribadi. Tegangan antara mendekat kepada Yesus Kristus dalam setiap doa menjadi kesempatan menyesuaikan diri dengan kehendak Yesus. Yang ditekankan di sini adalah aspek kedekatan relasi antara "Yesus Kristus Sang Jalan" dan masing-masing pribadi yang melewati jalan itu. Dari sini menjadi kentara aspek relasional yang tidak terpisahkan antara pribadi Yesus dan mereka yang melewati jalan-Nya. Setiap kali ada usaha 
untuk menjauh dari jalan itu, setiap kali pula ada kesempatan untuk kembali mendekat. Di sinilah aspek relasi pribadi mendapat tekanan.

Kristologi "Yesus Kristus Sang Jalan" berarti Yesus dialami sebagai pribadi yang selalu ada di dalam perjalanan. Ada saatnya orang melenceng dari jalan yang benar, tetapi pada saat yang sama orang selalu sadar bahwa Sang Jalan tetap ada dan siap untuk didekati. Yesus Kristus yang sungguh Allah dan sungguh manusia itu tidaklah jauh dari pergulatan harian para penghayat kebatinan Katolik. Ia tetap dekat dalam dua arti. Pertama, Yesus Kristus dekat karena perjalanan hidupnya sejauh dialami sebagai manusia adalah perjalanan hidup yang manusiawi yang bisa diikuti. Kedua, Yesus tetaplah Tuhan yang bisa hadir di dalam segala sesuatu. Ia hadir dan menyapa melalui perasaan manusia, bisa ditemui di mana pun dan kapan pun. Namun, seperti dimengerti oleh Mircea Eliade, orang-orang perlu memberi waktu dan tempat khusus untuk mengalami kehadiran Allah di dalam kehidupan hariannya. Pendekatan ini penting untuk menjaga agar setiap pribadi tidak semakin menjauh dari "Yesus Kristus Sang Jalan". Ketika kedekatan jalan itu dialami, maka Allah yang jauh itu tidak tampak jauh melainkan menjadi pribadi yang dekat dan dialami secara pribadi. Dalam bahasa yang lebih sederhana, orang tidak kehilangan arah mengenai jalan mana yang hendak dilewati.

Arus dunia yang dirumuskan oleh FABC sebagai 'pembawa ketidakselarasan' membuat orang bingung. Dalam situasi semacam setiap pribadi pengikut "Yesus Kristus Sang Jalan" mengakarkan kehidupan hariannya pada ajaran Yesus sejauh tertulis dalam Kitab Suci. Selain itu, penekanan pada tradisi Jawa mengakarkan hidup para pengikut "Yesus Kristus Sang Jalan" pada kasanah budaya setempat. Dengan demikian setiap pribadi menjadi mantap dengan hidup yang mereka jalani. Mantap bukan berarti hanya untuk diri sendiri saja. Mantap berarti siap untuk menjadi bagian dari proses 'membawa keselarasan bagi dunia'. Dalam karya-karya sederhana seperti dibuat oleh Yesus (menyembuhkan orang sakit, mengunjungi mereka yang berduka, memberi makan kepada yang lapar, dsb.) setiap pribadi pengikut "Yesus Kristus Sang Jalan" didorong untuk mengikuti teladan hidup Yesus. Di sinilah dimensi sosial dari kristologi "Yesus Kristus Sang Jalan" mendapat penekanannya.

Tetap disadari bahwa setiap pribadi amat mungkin mengalami kegamangan dalam hidup. Rumusan "Yesus Kristus Sang Jalan" menekankan aspek relasi personal. Yesus Kristus menjadi tempat tukar pendapat tentang kehidupan. Untuk itulah waktu dan tempat khusus dibutuhkan agar setiap pribadi dibantu mendekat kepada jalan menuju Bapa. Relasi personal dengan Yesus Kristus ini menjadi sebuah seni yang mengilhami bagaimana berjalan di dalam kehidupan. Ada tarik ulur di dalam kehidupan, ada saat-saat harus mundur dari keramaian, ada saat-saat harus bertindak dengan tegas, ada saatnya berbagi, ada saatnya mencintai keluarga, ada saatnya hidup di tengah-tengah masyarakat, ada saatnya bergulat dengan diri sendiri dan ada banyak hal yang lain yang perlu dihidupi. Untuk menentukan langkahlangkah kehidupan itu, olah batin mendapatkan tempatnya. Dalam proses ini terjadi seni berelasi dengan Allah. Seperti halnya berlatih gitar, awalnya sulit, tetapi seiring kebiasaan orang bisa memainkannya tanpa berpikir. Bahkan orang lalu bisa menciptakan lagu-lagu yang baru. Demikianlah proses pengolahan batin dan relasi dengan Yesus Kristus Sang Jalan menginspirasi orang untuk menciptakan seni hidup. Ia bisa menjalani kehidupan dengan cara yang untuk terus berjalan menuju kepada Bapa.

\section{SARAN PASTORAL}

Sejak awal pendekatan yang tepat bagi masyarakat Jawa adalah pendekatan mistik. Belajar dari pewartaan Islam pun, kita melihat bahwa pendekatan mistik adalah pendekatan yang paling mudah untuk menyapa rasa perasaan beriman masyarakat Jawa. Ketepatan rumusan dan juga keketatan ritual tidak mudah diterima oleh masyarakat Jawa. Memang akhirnya ada pendekatan ajaran Gereja yang mendekatkan pengajaran dan pendekatan pewartaan iman sesuai dengan hukum dan ajaran 
Gereja, namun pendekatan berdasarkan relasi mistik tidak pernah bisa dihilangkan. Wayang Gereja KAS tampak meninggalkan pendekatan mistis ini sehingga ada kesan Gereja kurang membumi. Menjauhnya para penghayat Kebatinan Katolik dari Gereja menjadi salah satu catatan. Meski ada temu kebatinan, tetapi pendekatan ini hanya menyentuh sebagian kecil umat saja. Maka, perlu dipikirkan cara-cara berpastoral yang mengembangkan tradisi mistik secara lebih luas, baik itu belajar dari tradisi lokal Jawa maupun dari warisan mistik Katolik yang ada. Baik apabila pengolahan iman dalam Temu Kebatinan menjadi hal yang bisa dibagikan kepada umat dalam kalangan yang lebih luas. Pendekatan ini selain menyumbang bagi "pengenalan umat akan tradisi budayanya', juga berguna bagi sebuah pastoral yang mengena pada umat setempat.

Dalam konteks penghayat kebatinan Katolik, sejak awal tujuannya adalah mencoba menyapa mereka dengan cara pengolahan batin mereka. Maka, keterbukaan akan pergulatan dan cara pengolahan batin mereka menjadi penting. Jangan sampai kita lalu jatuh pada ekstrim menjadi sebuah kepastian. Kekhasan kristologi "Yesus Kristus Sang Jalan" adalah menghargai proses untuk kemudian saling memperkaya satu dengan yang lain. Dalam bahasa Moltman, ini disebut sebagai berteologi dalam proses. Dalam hal ini, pemimpin Gereja memegang peran ganda. Mereka berperan sebagai bagian dari umat tetapi juga mempunyai peran seperti halnya Yesus sebagai seorang pengajar. Belajar dari Yesus, maka proses pengajaran dan pendampingan pastoral untuk para peng-hayat kebatinan Katolik bukanlah pendam-pingan yang menentukan apa yang harus dilakukan dan apa yang tidak. Belajar dari pengajaran Yesus, Yesus memulai pengajaran dengan memberdayakan para rasulnya. Pengalaman yang paling jelas adalah pengalaman ketika Yesus memberi makan 5000 orang. Yesus dalam peristiwa itu tidak menentukan tindakan apa yang harus dilakukan. Dalam peristiwa itu dikatakan:

Menjelang malam, murid-murid-Nya datang kepada-Nya dan berkata: "Tempat ini sunyi dan hari sudah mulai malam.
Suruhlah orang banyak itu pergi supaya mereka dapat membeli makanan di desadesa." Tetapi Yesus berkata kepada mereka: "Tidak perlu mereka pergi, kamu harus memberi mereka makan." Jawab mereka: "Yang ada pada kami di sini hanya lima roti dan dua ikan." (Mat 14:15-17)

Dari kisah ini menjadi jelas bahwa Yesus hanya menunjukkan hal utama yang harus dilakukan yaitu "memberi mereka makan". Tentang caranya bagaimana, Yesus memberi kebebasan kepada mereka. Rupanya hal yang kemudian dilakukan oleh para murid muncul dari apa yang ada dalam diri mereka. Kerelaan untuk memberikan kelima roti dan kedua ikan merupakan wujud persembahan mereka kepada Yesus untuk memberi makan sesamanya. Persembahan ini lalu digandakan oleh Yesus dan bisa memberi makan banyak orang. Peristiwa ini merupakan mukjizat yang nyata yaitu saat persembahan tulus membuahkan kerjasama antara Allah dan manusia. Demikian pula ketika memberikan kepada orang banyak, Yesus tidak melakukannya sendiri melainkan memberi kesempatan kepada para murid untuk berperan serta. Dikatakan, "Lalu disuruhNya orang banyak itu duduk di rumput. Dan setelah diambil-Nya lima roti dan dua ikan itu, Yesus menengadah ke langit dan mengucap berkat, lalu memecah-mecahkan roti itu dan memberikannya kepada muridmurid-Nya, lalu murid-murid-Nya membagi-bagikannya kepada orang banyak" (bdk. Mat 14:19). Dalam hal ini pendekatan pastoral kemuridan Yesus adalah mendampingi arah refleksi dan memberdayakan dalam karya. Tidak ada keharusan untuk membagikan makanan, tetapi ada petunjuk jelas untuk mencintai sesama. Demikianlah para pemimpin Gereja bisa belajar dari Yesus. Pastoral mendampingi arah refleksi utama dan memberdayakan dalam karya berangkat dari refleksi atau pun kemampuan mereka menjadi sarana bantu yang ampuh untuk memaknai kehidupan.

Penghayat kebatinan Katolik pada umumnya adalah pribadi-pribadi yang mempunyai kesadaran akan pentingnya membangun relasi pribadi dengan Yesus Kristus dan berkarya bagi sesama. Hanya 
bagaimana pemaknaannya dalam pendampingan Gereja, itulah yang perlu didampingi. Pendekatan yang dimulai berdasarkan nalar, berdasarkan pemikiran dalam arti mengutamakan aspek kebenaran berpikir bukan pendekatan yang pas dalam hal ini. Yang paling memungkinkan adalah pendekatan dengan mendasarkan pada perasaan dekat sebagai teman seperjalanan. Bukan pertama-tama menunjukkan apa yang harus dan apa yang tidak melainkan ada wawan rembug, dialog dan pemaknaan bersama yang lebih hidup. Dalam suasana semacam itu, kasanah pemaknaan Jawa maupun ajaran Gereja bisa saling melengkapi.

Belajar dari Pater van Lith yang memerlukan waktu lama dalam menterjemahkan doa-doa dasar, proses mengakarkan iman dalam hidup umat adalah sebuah proses. Selalu ada antitesis baru dalam sintesis yang dihasilkan antara tesis dan antitesis lama. Proses ini adalah proses yang berjalan terus menerus dan memerlukan pembelajaran dari hari ke hari. Hal ini mengingat relasi batin antara manusia dan Allah juga berjalan terus menerus dan tidak berhenti, demikian juga pendampingan kepada para penghayat kebatinan Katolik. Gereja perlu mengangkat kelebihan proses mereka yang selalu mengadakan wawan rembug dengan Allah untuk menentukan tindakan apa yang harus dilakukan dan peran apa yang perlu dimainkan. Di sinilah artinya pendampingan pastoral secara berkesinam-bungan dan memberdayakan. Meski ada kerangka besar "Yesus Kristus Sang Jalan", tetapi tentang refleksi mendetil dan tindakan harian selalu terbuka kemungkinan untuk terus dieksplorasi. Dengan demikian, kristologi "Yesus Kristus Sang Jalan" membuka kemungkinan terus menerus sesuai konteks dalam menanggapi Sabda Yesus Sang Jalan.

Belajar dari usaha pengolahan batin penghayat kebatinan Katolik ditemukan bahwa 'Yesus Kristus Sang Jalan' adalah tonggak yang mempersatukan penghayatan lokal dan ajaran iman Katolik. Karena itu, pengolahan batin para penghayat Kebatinan Katolik mendukung pengenalan akan Yesus Kristus sebagai tokoh sentral kekatolikan. Allah tetap menjadi tujuan utama dari peziarahan para penghayat Kebatinan Katolik. Maka, usaha ini baik untuk diteruskan.

\section{Martinus Joko Lelono}

Alumnus Magister Teologi Universitas Sanata Dharma Yogyakarta

Email:martinusjoko@gmail.com

\section{CATATAN AKHIR}

1 Rumusan 'penghayat Kebatinan Katolik' digunakan untuk menyebut mereka yang menghayati iman Katolik yang menghidupi tradisi kebatinan. Rumusan ini digunakan dalam Temu Kebatinan Katolik. Setiap pribadi mempunyai hati, batin dan dengan hati/batin, jiwa yang hening, bersih dan suci kita mau menggapai Tuhan, dan tinggal semakin erat dalam Tuhan. (wawancara dengan Rm. A. Budi Purnomo, Pr, ketua Komisi HAK Keuskupan Agung Semarang $2006-\ldots .$.$) .$

2 J. Darminta, SJ., "Kebatinan Kristiani Dilihat Sebagai Hidup Teologal", Mawas Diri, (Agustus 1987): 36-37.

3 Tim KOMHAK-KAS dan Majalah Inspirasi, Lentera yang Membebaskan, Mengalami kehadiran Tuhan dalam Keheningan Olah Batin dalam Terang Iman Katolik, KOM HAK KAS dan Majalah Inspirasi, Lentera yang Membebaskan, Semarang (2010): 61.

4 Tim KOMHAK-KAS dan Majalah Inspirasi, Lentera yang Membebaskan, Mengalami kehadiran Tuhan dalam Keheningan Olah Batin dalam Terang Iman Katolik, 27.

5 Kita lihat misalnya agama Yahudi yang mengacu pada pewahyuan YHWH kepada Abram, Kekristenan yang mengacu pada kehadiran Yesus di dunia sebagai wahyu Allah sertai agama Islam yang mengacu pada wahyu kepada Muhammad dalam bentuk kitab Al-Qur'an.

6 Pembahasan mengenai tokoh ini kita dasarkan terutama pada buku The Sacred and the Profane dengan subjudul The Nature of Religion. Sementara buku-buku lain menjadi pendukung.

7 Adolf Heuken, "Van Lith, Frans G. I. M.", dalam Scott W. Sunquist, "A Dictionary of Asian Christianity, 870 .

8 Tom Jacobs, "Frans Van Lith: Perintis Gereja yang Baru”, Majalah Rohani, (November 1984).

9 JB. Banawiratma, SJ, "Kristologi Kontekstual", Orientasi Baru, Pustaka Filsafat dan Teologi, 8, (1994): 234.

10 Mircea Eliade, The Sacred and The Profane, The Nature of Religion, The Significance of Religious myth, symbolism, and ritual within life and culture, (New York: Harper and Row, Publishers, 1910), 36.

11 Mircea Eliade, The Sacred and The Profane, The Nature of Religion, The Significance of Religious myth, symbolism, and ritual within life and culture,18. 
12 Francis J. Moloney, S.D.B, The Gospel of John, Sacra Pagina Series volume IV, (Minesota:Michael Glazier Book, 1998), 394-395.

13 Francis J. Moloney, S.D.B, The Gospel of John, 44-46.

14 Francis J. Moloney, S.D.B, The Gospel of John, 106-107.

15 John Marsh, Saint John, The Pelican New Testament Commentaries, (Middlesex: Pelican Books, 1968), 504.

16 FABC, Dokumen Sidang-Sidang Federasi Konferensi-Konferensi Para Uskup Se-Asia tahun 1995, (Jakarta: Departemen Dokumentasi dan Penerangan KWI, 1997), 293-295.

\section{DAFTAR RUJUKAN}

\section{Sumber Buku}

Amaladoss, Michael, The Asian Jesus, New York: Orbis Books, Maryknoll, 2006.

Banawiratma, JB., Yesus Sang Guru, Pertemuan Kejawen dengan Injil, Yogyakarta: Kanisius, 1977.

Cahyadi, T. Krispurwana, Yohanes Paulus II, Gereja, Teologi dan Kehidupan, Jakarta: Obor, 2007.

Dewan Karya Pastoral Keuskupan Agung Semarang, Gereja yang Signifikan dan Relevan, Pendalaman Ardas KAS 2011-2015, Muntilan: Dewan Karya Pastoral KAS, 2011.

Dhavamony, Mariasusai, Fenomenologi Agama, Yogyakarta: Kanisius, 1995.

Eliade, Mircea, The Sacred and The Profane, The Nature of Religion, The Significance of Religious myth, symbolism, and ritual within life and culture, New York: Harper and Row, Publishers, 1910.

, Symbolism the Sacred and the Arts, New York: Crossroad, 1907.

, The Sacred and The Profane, The Nature of Religion, The Significance of Religious myth, symbolism, and ritual within life and culture, Harper Torchbooks, New York, 1959.
Fenton, John Anthony Hot, The Way, The Truth, The Life, New York Chambridge University Press, 2009.

Furnish, Victor Paul, The Love Command in the New Testament, Nashville, TN: Abingdon Press, 1972.

Groenen, C., Sejarah Dogma Kristologi, Perkembangan Pemikiran Tentang Yesus Kristus pada Umat Kristen, Yogyakarta: Kanisius, 1988.

Leaman, Oliver, Eastern Philosophy, Routledge, London and New York, 2000

Maksum, Ali, Pengantar Filsafat, dari Masa Klasik hingga Posmodernisme, ArRuzz Media, Yogyakarta, 2012.

Marsh, John, Saint John, The Pelican New Testament Commentaries, Middlesex: Pelican Books, 1968.

Moloney, J. Francis S.D.B, The Gospel of John, Sacra Pagina Series volume IV, Minesota: Michael Glazier Book, 1998.

Moltmann, Jurgen, The Way of Jesus Christ, Christology in Mesianic Dimension, London: SCM Press, 1990.

Rahner, Karl, Everyday Faith, New York: Herder and Herder, 1968.

, The Love of Jesus and Love of Neigbour, New York: Crossroad,1983.

, 'Experience the Spirit' in The Practisce of Faith, New York: Crossroad, 1983.

, 'Teresa of Avila: Doctor of the Church', in The Great Church Year, edited by Albert Raffelt and Harvey D. Egan, New York: Crossroad, 1993.

Rosariyanto, Fl. Hasto, S.J., Van Lith, Pembuka Pendidikan Guru di Jawa, Sejarah 150 tahun Serikat Yesus di Indonesia, Yogyakarta, Penerbit Universitas Sanata Dharma, 2009 
Sahas, Daniel J., John of Damascus, The Heresy of The Ishjaeoities, Leiden: E. H. Brill, 1972.

Schreiter, Robert J., C. PP.S, Rancang bangun Teologi Lokal, Jakarta: BPK Gunung Mulia, 2006.

Simuh, Sufisme Jawa, Transformasi Islam ke Mistik Kejawen, Yogyakarta, Bentang Budaya, 2002.

Sugiyono, Metode Penelitian Kombinasi, (Mixed Methods), Bandung: Penerbit Alfabeta, 2012.

Susanto, P.S. Hary, Mitos Menurut Pemikiran Mircea Eliade, Yogyakarta: Kanisius, 1987.

Tim KOM HAK-KAS dan Majalah Inspirasi, Lentera yang Membebaskan, Mengalami kehadiran Tuhan dalam Keheningan Olah Batin dalam Terang Iman Katolik, Semarang: KOM HAK KAS dan Majalah Inspirasi, Lentera yang Membebaskan, 2010.

Vriens, G.S.J., Sejarah Gereja Katolik Indonesia I, Jakarta: Bagian Dokumentasi Penerangan Kantor Waligereja Indonesia Taman Cut Mutiah 10, 1972.

Witherington, Ben, Smyt and Helwys Bible Commentary, United States of America: Matthew,Smyth \& Helwys, 2006.

Zoetmulder, P.J. SJ, Manunggaling Kawula lan Gusti, Pantheisme dan Monisme dalam Sastra Suluk Jawa, Jakarta: Gramedia, 1969.

\section{Majalah}

Amaladoss, Michael, "Inkulturation Andi Internationality", East Asia Pastoral Revies, 29/3 (1992).

"Foreign Mission Today", East Asia Pastoral Revies, 2 (1988).

"Beyond Inculturation, Can the Many be One?", Vidyajyoti Education and Welfare Society, New Delhi (1988).
Banawiratma, JB., , "Kristologi Kontekstual", Orientasi Baru, Pustaka Filsafat dan Teologi, 8, Kanisius, Yogyakarta (1994).

Beyer, Gerald J., 'Karl Rahner on the Radical Unity of Love of God and Neighbour', Irish Theology Quarterly, vol. 68/3, Ireland (2003).

Decloux, Simon SJ., "Amal, My Friend", Vidyajoti Journal of Theological Reflection, Vol. LX, No. 2, (1996).

Harvey, D. Egan, 'The Mystical Theologi of Karl Rahner', The Way, (2013).

Hendarto, Y. Heru, "Romo Frans Van Liht, SJ., Pembaharu Karya Missi Gereja di Jawa Tengah", Majalah Rohani, (1990).

Jacobs, Tom, "Frans Van Lith: Perintis Gereja yang Baru", Majalah Rohani, (1984).

"Misi dan Kristologi", Orientasi Baru, Pustaka Filsafat dan Teologi, No 5, Kanisius, Yogyakarta (1991).

Koning, Robin, "Learning From Asia in Asia", The Jesuits In Asia Pacific 2014, The Jesuit Conference of Asia Pacific, Manila, Philippines (2014).

Louth, Andrew, "St. John Damascene as Monastic Theologian", The Downside Review, Volume 125 No. 440 (2007).

Rahner, Karl, "Reflection on the Unity of the Love of Neigbour and the Love of God", in Karl-H. Kruger and Boniface Kruger (trans), Theological Investigations, vol VI, Longman and Todd (1969).

'On Theology of Worship', Theological Investigation, Voume 19 (1969).

'Christian Living Formerly and Today', Theological Investigation, Volume 7, translated by David Bourke, New York, Herder and Herder (1971). 
The Catholic Bishop's Conference of Japan, , "The Process of Preparation of The Response", Responses of The Lineamenta, Orbis Books, Maryknoll, USA, (2000).

The Catholic Bishop's Conference of Indonesia, "Challenges to Evangelization", Responses of The Lineamenta, Orbis Books, Maryknoll, USA (2000).
Wilfred, Felix, "FABC, Orientasi, Tantangan-Tantangan, Dampak-Pengaruh", Dokumen Sidang-Sidang Federasi Konferensi-Konferensi Para Uskup Asia, 1992-1995, Dewan Komunikasi dan Penerangan Konferensi Waligereja Indonesia, Jakarta (1997).

Yun-ka Tan, Jonathan, "Theologizing at The Service of Life", FABC PAPER, 108. 